\title{
Corrosion of silicon integrated circuits and lifetime predictions in implantable electronic devices
}

\author{
A. Vanhoestenberghe ${ }^{1}$ and N. Donaldson ${ }^{1}$ \\ ${ }^{1}$ Implanted Devices Group, Department of Medical Physics and Bioengineering, \\ University College London - WC1E 6BT London, UK \\ E-mail: a.vanhoest@ucl.ac.uk
}

\begin{abstract}
Corrosion is a prime concern for active implantable devices. In this paper we review the principles underlying the concepts of hermetic packages and encapsulation, used to protect implanted electronics, some of which remain widely overlooked. We discuss how technological advances have created a need to update the way we evaluate the suitability of both protection methods. We demonstrate how lifetime predictability is lost for very small hermetic packages and introduce a single parameter to compare different packages, with an equation to calculate the minimum sensitivity required from a test method to guarantee a given lifetime.

In the second part of the paper, we review the literature on the corrosion of encapsulated integrated circuits (ICs) and, following a new analysis of published data, we propose an equation for the pre-corrosion lifetime of implanted ICs, and discuss the influence of the temperature, relative humidity, encapsulation and field-strength. As any new protection will be tested under accelerated conditions, we demonstrate the sensitivity of acceleration factors to some inaccurately known parameters. These results are relevant for any application of electronics working in a moist environment. Our comparison of encapsulation and hermetic packages suggests that both concepts may be suitable for future implants.

Keywords: corrosion, lifetime prediction, micropackaging, IC protection, implantable electronic devices, accelerated ageing tests.
\end{abstract}

PACS numbers: 81.65.Km, 81.65.Rv, 87.85.E-, 87.85.Va

Submitted to: J. Neural Eng. 


\section{Contents}

1 Introduction 3

2 Protection of electronics for implantable devices 4

2.1 Hermetic packages . . . . . . . . . . . . . . . . 4

2.1.1 Lifetime estimations . . . . . . . . . . . . . . 5

2.2 Polymer encapsulation . . . . . . . . . . . . . . . . 7

3 Corrosion of integrated circuits $\quad 8$

3.1 Corrosive failures in bare ICs . . . . . . . . . . . . . . . . 9

3.1.1 Aluminium corrosion . . . . . . . . . . . . . . . . 9

3.1.2 Passivation layer corrosion . . . . . . . . . . . . . . 10

3.2 Corrosive failures in RTV coated ICs . . . . . . . . . . . . . . . . . . 11

3.2 .1 Water condensation . . . . . . . . . . . . . . 11

3.2 .2 The three routes to corrosion failure . . . . . . . . . . . . . 12

3.3 Influence of field-strength and current density . . . . . . . . . . . . . 14

4 Expected lifetime of implanted ICs $\quad 15$

4.1 Influence of the temperature . . . . . . . . . . . . . . . . 16

4.2 Influence of the relative humidity . . . . . . . . . . . . . . . . 17

4.3 Acceleration factors . . . . . . . . . . . . . . . . . . 18

5 Discussion $\quad 21$

6 Conclusion $\quad 22$ 


\section{Introduction}

Implanted neuroprostheses continue to pose a major challenge to the bioengineer. On one hand, their success means that some (e.g. cochlear stimulators) are now being implanted in infants, so the devices ought to be reliable enough to work for close to a century in the body. On the other hand, the ever-shrinking dimensions afforded by integrated circuit technology open the potential of increasing the functionality while decreasing the electrodes' size to approach the dimensions of their target neurons. The challenge therefore is to both raise the reliability, and, simultaneously, reduce the size of the device, without jeopardizing safety.

Suitable methods for the long-term protection of the electronics in new, smaller, implantable devices are still to be developed. Consequently, promising research may stall or be interrupted after obtaining proof of principle because of the lack of a reliable packaging solution. For example, Lertmanorat et al. (2009) encapsulated an integrated circuit (IC) and several surface mount components in epoxy to form an active electrode mount and demonstrate the feasibility of a stimulation method they had developed: fascicular selective stimulation. The cuff produced was too rigid and the authors highlighted the need for a micropackaging method suitable for long-term human implantation, hence this device is yet to be tested in a long-term human trial. Likewise, Zrenner et al. (2009) and Rothermel et al. (2009) report on the first active subretinal electrodes to be implanted in humans. Their light-sensitive ICs were coated in silicone rubber and implanted in the eyes of patients for four-week long trials, at the end of which they were removed. No actual reason for removing the implants is given, although Rothermel states that: "The guaranteed lifetime of the devices had to be only 2 months, after that period all implants were completely removed and analysed.", indicating an awareness of their packages' limitation. While the publication of such exciting results demonstrates how far the electronic technology has evolved, it also stresses the critical role of the packaging. There is currently a need, in neuroprosthetics and elsewhere, for novel methods for protecting the ever smaller electronic components: this need is regularly mentioned in papers (Ng et al. 2009, Gerding 2007, Rizzo et al. 2001).

In this paper the methods used in the commercial production of implantable electronic devices are discussed to evaluate their ability to meet the conflicting challenges of miniaturisation and increased reliability. We explain how these have lead to the loss of lifetime predictability until now afforded by hermetic packages. Combining this with the increasing use of bare ICs with high integration density in implantable electronics requires a new understanding of the drivers of corrosion over silicon devices in moist environments. We review the literature and establish the influence of the field-strength and passivation layer stoichiometry on reliability. Finally, we discuss the contribution of the temperature and relative humidity to the lifetime and use the new equation to compare the two methods, hermetic enclosure and polymer encapsulation, on their suitability to protect bare ICs for long-term implantation. 


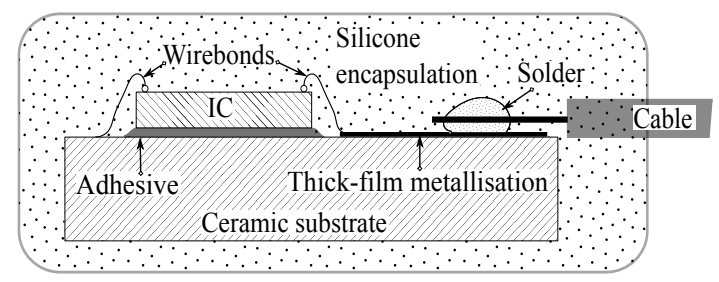

(a) Conformal layer or encapsulation.

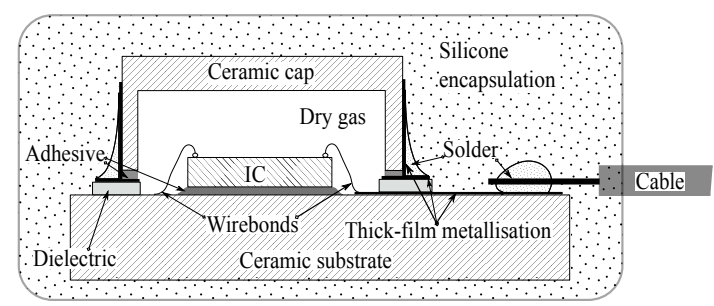

(b) Impermeable envelope or hermetic packaging.

Figure 1. Sketches comparing examples of the conformal layer (a) and hermetic packaging (b) as methods of protecting an IC for human implantation.

\section{Protection of electronics for implantable devices}

Corrosion is a cause of failure in many electronics applications (Lantz \& Pecht 2003, Qi et al. 2008, Zhao \& Pecht 2003). It is influenced by the presence of liquid water, temperature and voltage bias, hence is particularly relevant in implantable electronics that operate surrounded by body fluids (Bowman \& Meindl 1986). In 1976, P.E.K. Donaldson, working in the nascent field of neuroprostheses, identified two options for the protection of implantable electronics: "the conformal layer" and "the impermeable envelope" (Donaldson 1976), also called encapsulation and hermetic enclosure respectively. Figure 1 shows examples of both types, which are introduced in more details in the following two subsections.

\subsection{Hermetic packages}

Hermetic packages rely on a solid shell, made of a water-impermeable material and hermetically sealed, to protect the electronic components by maintaining them in an atmosphere with a low relative humidity. Contribution to the internal water content may come from water trapped within the package before and during sealing (including outgasing of adsorbed molecules). Further water molecules as well as other ions present in the environment may penetrate the enclosure either by diffusion through the walls or via cracks (Thomas 1976). No package is completely hermetic, rather, a notion of "sufficiently hermetic" would be more appropriate. For packages that are to remain dry inside for decades after implantation, the materials used must be very impermeable to water vapour. The candidates are glasses, ceramics and metals, the latter being much the most common. The methods selected for sealing and for the electrical feedthroughs (for 
electrodes and other connections) also affect the hermeticity and initial water content. Silicone rubber on its own provides the protection when opting for the conformal layer (fig. 1(a)). It is however also commonly used in combination with hermetic encapsulation, figure 1(b), where it serves three purposes. (1) It does offer a biocompatible outer layer and covers the sharp edges of the rigid shell to protect the host's body. (2) It prevents corrosion of the exposed metal and (3) it insulates the feedthroughs, that carry the signals in and out of the sealed enclosure, as well as eventual wire connection sites such as the solder pad in 1(b). In pacemakers and other similarly packaged implants, most of the titanium shell, which can be made smooth enough, is exposed to the body fluids. This is acceptable as long as all exposed metal surfaces (including tracks) are at the same potential. Such implants sometimes use metal in glass feedthroughs although this is becoming less common.

\subsubsection{Lifetime estimations}

Sealed packages can be tested to estimate the rate of ingress of water vapour $R_{\mathrm{H}_{2} \mathrm{O}} \ddagger$. This leak rate can be used to infer the time for the relative humidity inside the package to reach a dangerous level, at which leakage and corrosion currents may become significant. Practically, a packaging unit can be characterised once to provide an estimate of the lifetime of the implants it produces. The constance and quality of the packaging process is then monitored by regular, random, tests of packaged products. Although different test methods exist, they all have a limited sensitivity. Because of this limitation, a package regarded as non-leaky could indeed become saturated with water vapour (Vanhoestenberghe \& Donaldson 2011). The importance of this limitation cannot be understated, as it may lead to incorrect interpretation of the leak test results and acceptance of actually unsuitable packages (Sinnadurai 1996). This is critical as the lifetime prediction gives confidence in the hermetic protection method, and seems to have been instrumental in its commercial adoption (Bowman \& Meindl 1986).

If water vapour enters a package of volume $V$ at a rate $R_{H_{2} O}$, the internal partial water vapour pressure $P_{H_{2} O \text {,in }}$ will increase over time according to equation:

$$
t_{1}-t_{0}=\frac{V}{R_{H_{2} O}} \ln \left(\frac{\Delta P_{H_{2} O, t_{0}}}{\Delta P_{H_{2} O, t_{1}}}\right)
$$

where $\Delta P_{\mathrm{H}_{2} \mathrm{O}, t_{i}}=P_{\mathrm{H}_{2} \mathrm{O} \text {, out }}-P_{\mathrm{H}_{2} \mathrm{O} \text {, in }}$ is the water vapour pressure difference, between the internal and external environment, at instant $t_{i}$. While equation 1 is suitable to estimate the time to reach a given internal water vapour pressure, it is also interesting to express the internal water vapour pressure variation with time. As $P_{\mathrm{H}_{2} \mathrm{O} \text {,out }}$ is, at all times after implantation, $0.062 \mathrm{~atm}$, the saturation pressure of water vapour at $37^{\circ} \mathrm{C}$ and $1 \mathrm{~atm}$ (in the case of a package implanted in the human body), equation 1 leads to equation 2, where $P$ stands for $P_{\mathrm{H}_{2} \mathrm{O}}$, and the time constant $\tau=V / R_{\mathrm{H}_{2} \mathrm{O}}$.

$\ddagger$ The value for the water vapour leak rate, expressed in units of volume per unit of time, is only true at a given temperature and pressure. For a discussion on leak rate units, see (Vanhoestenberghe \& Donaldson 2011). 


$$
P_{\text {in }, t}-P_{\text {in }, t_{0}}=\left(P_{\text {out }}-P_{\text {in }, t_{0}}\right)\left(1-e^{-\frac{t-t_{0}}{\tau}}\right)
$$

Introducing the relative humidity $R H=\frac{P_{\mathrm{H}_{2} \mathrm{O}}}{P_{s a t, \mathrm{H}_{2} \mathrm{O}}}$, equation 2 can be further re-arranged to express the change, with time, in a package's internal relative humidity.

$$
R H_{i n, t}-R H_{i n, t_{0}}=\left(1-R H_{i n, t_{0}}\right)\left(1-e^{-\frac{t-t_{0}}{\tau}}\right)
$$

The time constant $\tau$ indicates how long it will take for the internal water vapour pressure, $P_{H_{2} \text {, in }}$, to reach $63 \%$ of the external water vapour pressure. In other words, $\tau$ is the time it will take for the relative humidity inside the package to reach $63 \%$. It can be seen as a quality factor, offering a simple way to compare different packages. Equation 3 can be used to calculate the $\mathrm{RH}$ inside the package at any given time, provided the initial water vapour content is known. A package may then be deemed sufficiently hermetic if the time to reach an unacceptable water vapour pressure exceeds the intended lifetime. This $R H_{\text {crit }}$ can generally be defined as the humidity at which the corrosion rate changes, significantly reducing the reliability of the device. It is dependent on the specific application as the corrosion rate depends on the working temperature and applied voltage bias.

Because water molecules will have adsorbed on the internal surfaces of the package before it is sealed, the initial relative humidity is unlikely to be $0 \%$ even if the packaging atmosphere is dry. However, thoroughly drying all parts of the package can considerably lower it (Schuettler et al. 2011) hence increasing the dry life of the device. Figure 2 is a plot of the internal water vapour pressure variation with time for a package that is initially dry (starting at $0 \% \mathrm{RH}$ for simplicity) and maintained in water, or implanted in the body, at $37^{\circ} \mathrm{C}$. The curves show how the internal humidity changes for different values of the time constant $V / R_{\mathrm{H}_{2} \mathrm{O}}$. If the highest acceptable relative humidity is $R H_{\text {crit }}$ and the required lifetime $t_{\max }, \tau$ provides a simple test condition.

$$
\tau=V / R_{H_{2} O} \geq \frac{t_{\max }}{\ln \left(\frac{1}{1-R H_{\text {crit }}}\right)}
$$

The hermeticity of packages is most commonly evaluated in terms of their true helium leak rate $\left(L_{H e}\right) . \oint$ Knowing the working temperature $(T)$ and pressure $(P)$, and assuming the gases are ideal, the number of moles $(n)$ can be converted to a volume $V$ as $P \times V=n \times R \times T$ where $R$ is the ideal gas constant $82.057 \mathrm{~cm}^{3} \times a t m \times K^{-1} \times \mathrm{mol}^{-1}$. The true leak rate can thus be converted to a the flow of a volume of water vapour, at a given temperature and pressure, per unit of time. Somewhat confusingly since $R$ is the ideal gas constant, this rate is denoted by the letter $R_{H e}$. Conversion from $R_{H e}$ to $R_{H_{2} \mathrm{O}}$ is achieved using equation 5, which is adapted from Howl \& Mann (1965) and assumes a purely molecular flow through the leak. The symbols $\Delta P_{\mathrm{H}_{2} \mathrm{O}}$ and $\Delta P_{\text {tracer }}$ represent partial pressure differences, between the two sides of the package and $M_{x}$ is the molecular mass of the gas. For an implant, $\Delta P_{H_{2} O}=0.062 \mathrm{~atm}$. If using the true

$\S$ A leak rate is said to be true or standard when measured at $25^{\circ} \mathrm{C}$ and $1 \mathrm{~atm}$. It is represented as $L_{x}$ where $x$ indicates the gas leaking and the units are $\mathrm{mol} / \mathrm{s}$. 


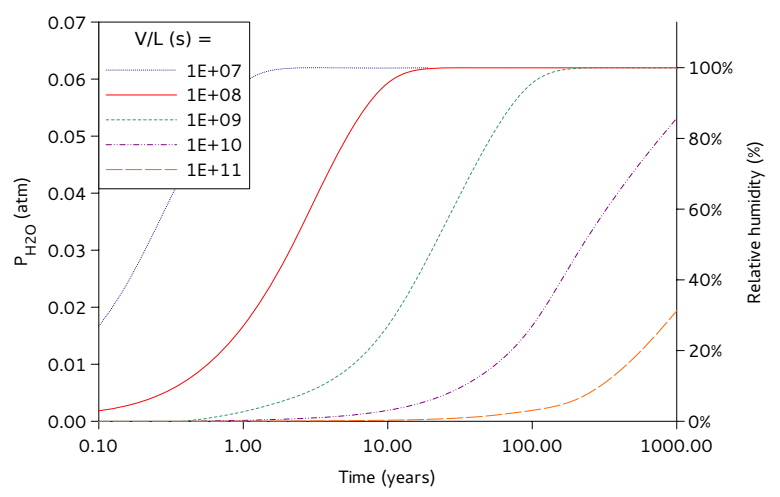

Figure 2. Partial water pressure (atm) and relative humidity (\%) as a function of implantation time for time constant $V / R_{H_{2} O}=10^{7} \mathrm{~s}, 10^{8} \mathrm{~s}, 10^{9}, 10^{10} \mathrm{~s}$ and $10^{11} \mathrm{~s}$. The saturation pressure of water at $37^{\circ} \mathrm{C}$ and $1 \mathrm{~atm}, P_{\mathrm{H}_{2} \mathrm{O} \text {, out }}=0.062 \mathrm{~atm}$.

helium leak rate $\Delta P_{H e}$ is $1 \mathrm{~atm}$, and $R_{H e}=L_{H e} \times R \times T$.

$$
\begin{aligned}
& R_{\mathrm{H}_{2} \mathrm{O}}=R_{\text {tracer }} \times \Delta P_{\mathrm{H}_{2} \mathrm{O}} / \Delta P_{\text {tracer }} \times \sqrt{M_{\text {tracer }} / M_{\mathrm{H}_{2} \mathrm{O}}} \\
& R_{\mathrm{H}_{2} \mathrm{O}}=L_{\mathrm{He}} \times 82.057 \times 310 \times 0.062 \times \sqrt{\frac{4}{18}}
\end{aligned}
$$

Using equation 6 in equation 4 gives the following condition on the true helium leak rate as a function of the package's volume (in $\mathrm{cm}^{3}$ ) and intended lifetime (in $\mathrm{s}$ ) at $37{ }^{\circ} \mathrm{C}$.

$$
L_{H e} \leq \frac{V \times \ln \left(\frac{1}{1-R H_{\text {crit }}}\right)}{743 \times t_{\max }}
$$

For example, taking $t_{\max }=100$ years and $R H_{\text {crit }}=35 \%$, to qualify a package with an internal volume of $1 \mathrm{~cm}^{3}$ by helium-leak testing, the minimum required sensitivity should be below $2 \times 10^{-13} \mathrm{~mol} / \mathrm{s}$, which is close to the limit for mass-spectrometers. In contrast, a package of $1 \mathrm{~mm}^{3}$ would require a sensitivity $\leq 2 \times 10^{-16} \mathrm{~mol} / \mathrm{s}$, which is undetectable.

Therefore, while it may be possible to make a mm-volume package sufficiently hermetic for long-term implantation, it is not possible to prove that it is so by tracer gas tests (Vanhoestenberghe \& Donaldson 2011). Hence, if $\mathrm{V} \leq 1 \mathrm{~mm}^{3}$, long-life predictability is lost.

\subsection{Polymer encapsulation}

The soft encapsulation is, to the best of our knowledge, only used by one medical implant company, Finetech Medical Ltd (UK). This option, however, can be highly reliable. When well-designed, with carefully chosen types of components, silicone rubber encapsulation can give mean times to failure of decades. This has been shown from records of patients implanted with the Finetech-Brinkley sacral nerve roots stimulator (Brindley 1994, Jezernik et al. 2002, Rijkhoff 2004). Compared with a hard hermetic shell, the soft encapsulation is attractive because of the lower tooling costs and ease of 
design alterations, making it especially well suited for small research groups looking for fast prototyping solutions (Jarvis \& Salmons 2001).

Silicone rubber encapsulation has been reviewed in details by P.E.K. Donaldson, see for example the series of four papers "Aspects of silicone rubber as an encapsulant for neurological prostheses" (Donaldson 1991, Donaldson \& Aylett 1995, Donaldson 1995, Donaldson 1997). Besides its most obvious role at preventing the ambient fluid from shorting conductors, a good encapsulation prevents long-term corrosion damage. How this can be, given that the rubber is indeed very permeable to water vapour, is answered in Donaldson (1991). Briefly, it relies on the low viscosity of the uncured rubber to flow in every detail of the surface, and on careful design and moulding to limit void formation and cohesive tension as the rubber shrinks while curing. Once implanted, the rubber quickly becomes saturated with water vapour (Traeger 1977), but if none of this vapour can condense into liquid water, corrosion will not take place. Cleanliness and absence of voids are essential. The underwater adhesion of the encapsulant to the substrate materials is also critical as it must remain strong for the required lifetime of the device. Voids in the rubber offer empty spaces in which the water vapour (saturating the rubber) may condense. Yet, as the liquid outside the implant is ionic, osmosis will drive water out of this pocket. Any ionic contamination inside the encapsulant, however, will lead to the formation of a highly concentrated solution, hence attracting more water (again, by osmosis), and increasing the pressure on the internal walls of the void, until equilibrium is reached, or the rubber bursts (Fedors 1980). If the water condenses over a contaminated site, a water bubble will form (see fig. 3). The water pressure will break the adhesive bonds between the rubber and the substrate, and progressively lift off more of the coating, leaving large areas exposed to the electrolyte, potentially leading to shorts between tracks and corrosion. If corrosion does occur, Donaldson et al. (2011) have shown that the corrosion products of tin, lead, copper, bismuth, chrome, nickel and zinc do not diffuse through silicone rubber at rates that would render the failed device toxic to the patient.

This protection method offers excellent reliability when using large discrete components in relatively simple circuits, carefully designed to maximise silicone rubber flow and minimise field strength. However, as bare ICs are now routinely included as part of an implant, it is essential to investigate whether silicone rubber encapsulation alone offers sufficient protection for bare dice, or whether the method may only be suitable for short to medium-term implants.

\section{Corrosion of integrated circuits}

Due to its impact on the reliability of most electronic devices, the failure of integrated circuits in high-humidity environment has been extensively studied. This section is a critical review of the literature on the influence of temperature, relative humidity and 


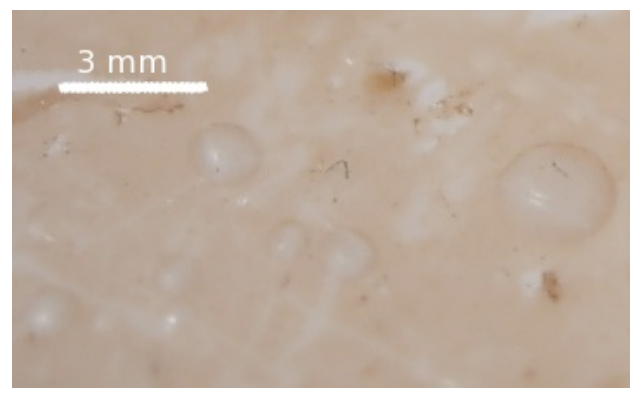

Figure 3. Water bubbles forming between an alumina substrate and a layer of silicone rubber (MED-1000, Nusil), after 500 days of immersion in boiling water at pH 7 .

applied bias on the corrosion of integrated circuits $\|$. Only results relevant to small active implantable devices and the protection methods discussed in section 2 are considered. In a hermetic package, the IC is exposed to an environment with an unknown relative humidity. The results of accelerated ageing studies on bare silicon devices are discussed in 3.1. If encapsulation is used, the situation is more complex. Experience has shown that silicone rubbers are the best encapsulants for the prevention of IC corrosion (Edell 2004). However, epoxy encapsulation, not silicone rubber, is much the more common with plastic packages and indeed they are the focus of most of the literature. Although epoxies are about 3 orders of magnitudes less permeable to water vapour than silicone rubber (Traeger 1977), the surface conductivities recorded are lower and more stable with silicone rubber, leading to lower failure rates (Sim \& Lawson 1979, Striny \& Schelling 1981). Yet, as silicone rubber has been used for several decades to protect ICs operating in moist environments (Balde 1991, Edell 2003, Wong et al. 1989), there exists a small subset of publications presenting experimental results from reliability studies including ICs coated with a room temperature vulcanising (RTV) silicone rubber. These are reviewed in subsection 3.2.

In this paper we have thus exclusively considered publications on the corrosion rate and reliability of ICs, with and without passivation, either bare or encapsulated in silicone rubber. In this context, the term encapsulation, used without further qualification, refers to silicone rubber encapsulation.

Unprotected polished silicon wafers corrode when exposed to body fluids (passive test pieces implanted for 6 months in rabbits (Edell 2004)). Although light p-doping can considerably slow the corrosion rate, to $\sim 1 \mu \mathrm{m} /$ month (or $1 \mathrm{~mm}$ in about 80 years), bare silicon should be further protected if implanted.

\subsection{Corrosive failures in bare ICs}

\subsubsection{Aluminium corrosion}

Aluminium is the most common metallisation of ICs. This metal becomes $\|$ It is not concerned with the corrosion of metal when used passively in implantable devices or elsewhere. 
spontaneously covered by a thin layer of $\mathrm{Al}_{2} \mathrm{O}_{3}$ which provides some protection from moisture. Corrosion of this surface in water has been thoroughly studied, yet the process in the presence of water vapour is not so well documented (Scamans \& Rehal 1979). Condensation (i.e. the presence of liquid water) appears necessary for degradation to take place while contamination and local $\mathrm{pH}$ influence the corrosion rate (DerMarderosian \& Murphy 1977, Iannuzzi 1983a). Olberg \& Bozarth (1976) demonstrated both chemical degradation and electrochemical corrosion, the rate of the latter being influenced by an applied bias. In Iannuzzi (1983b), the corrosion rate for very clean aluminium tracks was so low as to be undetectable, even after $12,597 \mathrm{~h}\left(1.4\right.$ years) at $85{ }^{\circ} \mathrm{C}$ and $85 \%$ $\mathrm{RH}$ with a $10 \mathrm{~V}$ bias. No change in the oxide thickness was observed. However, the work of Scammans, Bargeron and Flower suggests that failure would eventually result from hydration of the amorphous oxide layer, causing blistering, and precipitation of the aluminium hydroxide (Scamans \& Rehal 1979).

In a separate publication, Iannuzzi (1983a) showed the effect of a moderate $\mathrm{Cl}_{2}$ contamination of the atmosphere. Although there was a significant increase in the leakage current after a long diffusion period, all the devices (interdigitated combs with an interposed meander directly exposed to the atmosphere) failed due to corrosion at the pads where a gold wire was bonded. She concluded that galvanic corrosion at the $\mathrm{Au} / \mathrm{Al}$ interface was aided by the presence of $\mathrm{Cl}_{2}$ as it accelerated the dissolution of the passivating oxide. The failure rate was not related to the long-term leakage current readings. However, a sudden increase in leakage current was sometimes observed just before failure, indicating that although localised around the galvanic couple, the corrosion was dependent on local surface conduction.

If contaminants are present within a packaged device, even a few monolayers of water adsorbed on the surface may be sufficient to support corrosion under applied bias (Osenbach 1996). Nonetheless, careful cleaning (Iannuzzi 1981) and preventing water from condensing or even being adsorbed on a clean surface between two exposed metal areas, can slow the corrosion rate sufficiently even for the long lives expected from some medical implants.

If metal corrosion does occur, failure may result from an open circuit following the degradation of a track or from the functional shorting of two tracks by a low impedance electrolyte formed by the corrosion products in solution.

\subsubsection{Passivation layer corrosion}

Passivation layers usually cover the whole of the IC, with the exception of the connection pads, with a thin conformal coating. They are commonly made of silicon nitride $\mathrm{Si}_{3} \mathrm{~N}_{4}$ or silicon dioxide $\mathrm{SiO}_{2}$ although their exact composition and stoichiometry is variable. These offer some corrosion protection when the temperature and relative humidity are moderate. However, experimental evidence published in Osenbach \& Knolle (1992) shows that these materials also corrode under water, exposing the underlying aluminium tracks. The authors concluded that when exposed to liquid water, the passivation layer, whether containing only amorphous silicon nitride or amorphous 
silicon oxide, or a mix of both, does suffer a chemical degradation process, influenced by the stoichiometry of the film, temperature and local $\mathrm{pH}$. A thermal oxide layer under the $\mathrm{Si}_{3} \mathrm{~N}_{4}$, followed by a layer of either $\mathrm{SiO}_{2}$ or silicone rubber was observed in Edell (2004) to be the optimum combination to limit the corrosion rate. The latter is better because it is less susceptible to pinholes and cracks. This is important since if there is such a defect in the passivation layer, moisture may condense preferentially over the irregularity by capillarity, leading to earlier failure than for an unpassivated surface (Osenbach \& Zell 1993).

\subsection{Corrosive failures in RTV coated ICs}

We have shown so far that aluminium corrosion in the presence of water (forming an electrolyte) may be either purely chemical (no charged particles involved), or electrochemical. It is limited by the rate of ion transport and affected by the nature of the solution and the possible presence of a voltage bias (Iannuzzi 1981). When aluminium is protected by a passivation layer, the latter is also susceptible to degradation under water. This process is mainly chemical and influenced by temperature, stoichiometry and $\mathrm{pH}$.

The situation with encapsulated devices is more complex as the silicone rubber occupies the bonding sites otherwise available for the water molecules. To understand how failure occurs here, Osenbach (1993) investigated aluminium structures, passivated and coated with a room temperature vulcanising silicone rubber, and placed, biased, in a high temperature and high relative humidity environment, $85{ }^{\circ} \mathrm{C}$ and $85 \% \mathrm{RH}$. By analysing the cumulative times to failure of several sample sets, he identified 3 distinct routes for the degradation process (see section 3.2.2), each of which leads to functional failure. These all follow the same general pattern of water vapour condensation followed by destruction of the passivation layer when present, and further corrosion of the underlying metal. What differs amongst the failure modes is the area where water condenses: over exposed metal (bond pads) for type i failure or over the passivation layer for types (ii) and (iii). The difference between the latter is what drives the passivation layer destruction.

\subsubsection{Water condensation}

Silicone rubber is permeable to water vapour and in a high humidity environment the encapsulant quickly becomes saturated with it (Traeger 1977). Water may then condense on the underlying surfaces, either into a void or an area of poor adhesion of the encapsulant. Figure 4(a) illustrates this when a passivation layer is present, although this may happen over any other encapsulated surface. As osmosis will tend to drive pure water away from the nascent bubble, this process starts very slowly. Once corrosion starts however, the water is turned into an electrolyte and osmosis reverses the flow of water and the bubble grows faster. Likewise, water will condense around ionic contamination, without an initial loss of adhesion or void (fig. 4(b)). The resulting 
concentrated solution will quickly lead to the appearance of a considerable volume of liquid water, that will both support corrosion and contribute to the delamination of the encapsulant.

\subsubsection{The three routes to corrosion failure}

The three processes identified in Osenbach (1993) can be described as follows.

(i) The earliest failures are due to corrosion at some bond pads. This process is relatively fast as the passivation layer is not involved. Water condenses directly over the metal of the bond, and corrosion ensues. Hence the early life failures during Osenbach's accelerated ageing tests occurred within a few hundred hours. This failure rate is influenced by the applied voltage and the cleanliness of the sample prior to encapsulation (Iannuzzi 1983a).

(ii) The second and third types of failure are slower than (i) as they are due to condensation of water over the passivation surface. Initial condensation is followed by bias-driven attack at the silicone-passivation interface. At high field-strengths, an electron current flows through the passivation, allowing virtual electrodes to form at the silicone-passivation interface (fig. 4(c)). If a pocket of liquid water is present at the interface, and the bias is sufficient, electrolysis of water (fig. 4(d)) will cause $\mathrm{pH}$ changes that hasten the dissolution of the passivation and eventually the gas evolution may suffice to tear the encapsulant away, further enlarging the area exposed to water. This is then followed by corrosion of the underlying aluminium (fig. 4(f)).

(iii) The third type also requires condensation of water over the passivation layer. In areas without virtual electrodes, purely chemical dissolution of the passivation layer can occur (fig. 4(e)). As with type (ii), the process starts slowly as it depends on the water condensation. Mid-life failures will occur if ionic contamination leads to the formation of a concentrated ionic solution while later life failures will result from the presence of a void or loss of adhesion. As discussed in 3.2.1, once degradation starts, osmosis will cause further condensation. This will increase the pressure inside the water pocket, further weakening the adhesion of the encapsulant and enlarging the area exposed to liquid water. Again, this is eventually followed by corrosion of the underlying aluminium (fig. 4(f)). In this case only the subsequent aluminium corrosion is voltage sensitive. Note that in their experiments, Osenbach \& Zell (1993) excluded failures due to defects in the passivation layer (holes or stress-induced cracks). They screened and applied further processing to a subset of failed samples and found no indications of such causes of failure.

Type (i) causes early life failures, and can be avoided by thorough cleaning and careful encapsulation. Types (ii) and (iii), excluding mid-life failures due to ionic contamination, lead to later life failures. They compete in time, depending on the temperature, applied bias, stoichiometry of the passivation layer and the presence of adsorbed or liquid water. Neither corrosion processes will occur while there is no condensation site at the surface 


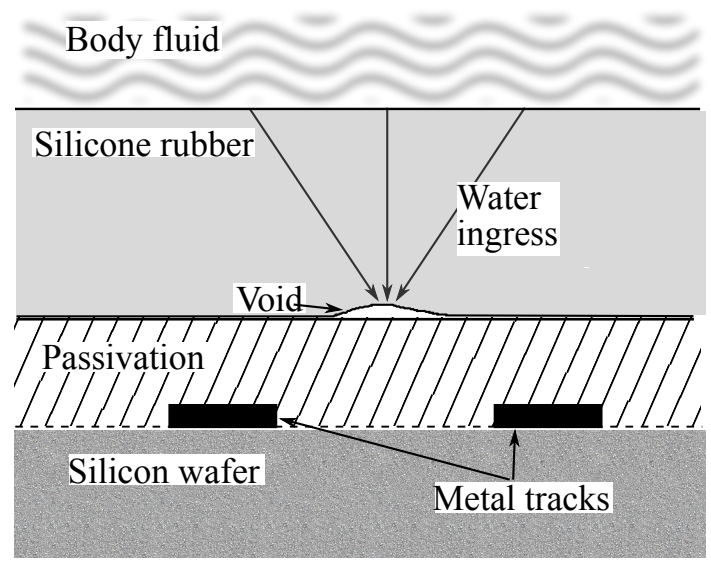

(a) How water condenses at the interface: void or loss of adhesion.

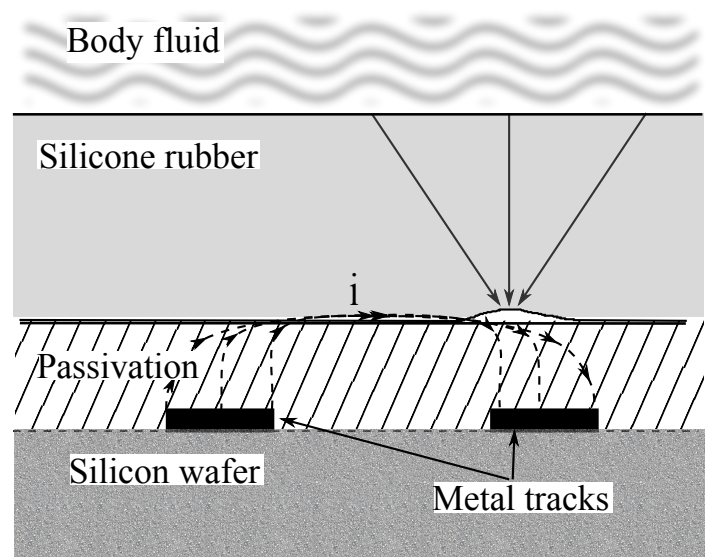

(c) Failure type (ii): electron current at the silicone rubber-passivation interface creates virtual electrodes above the metal tracks, and a void is present at the interface.

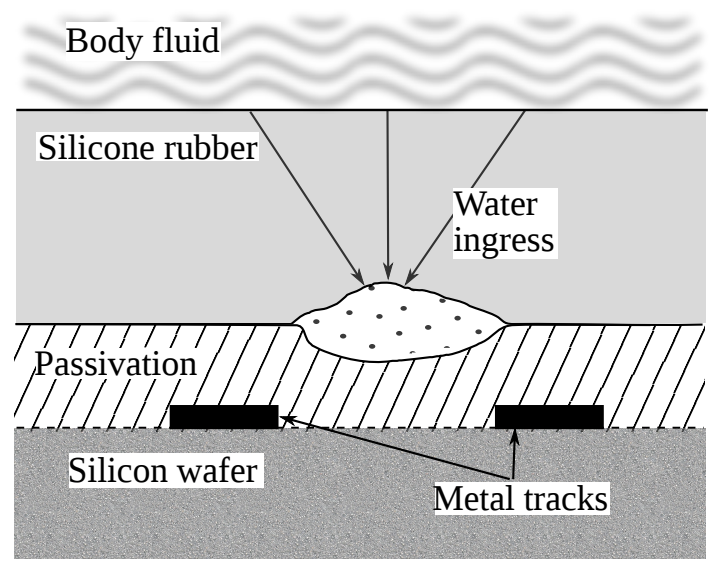

(e) Failure types (iii): the water at the interface causes chemical degradation of the passivation layer.

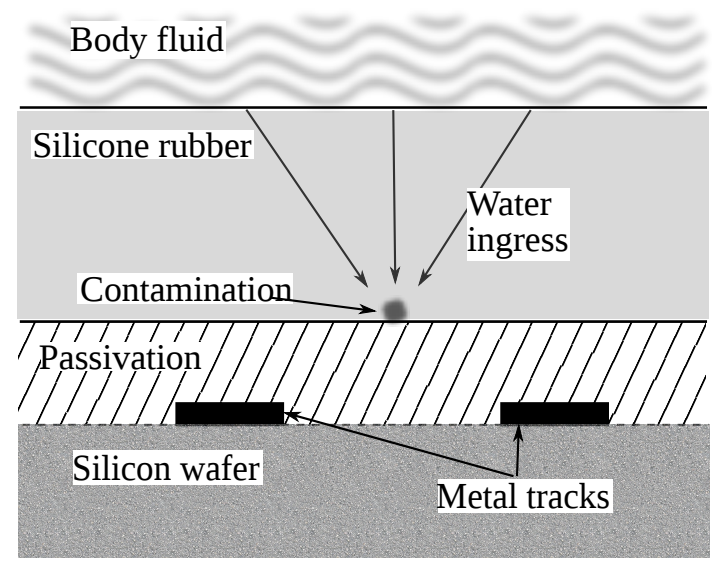

(b) How water condenses at the interface: ionic contamination.

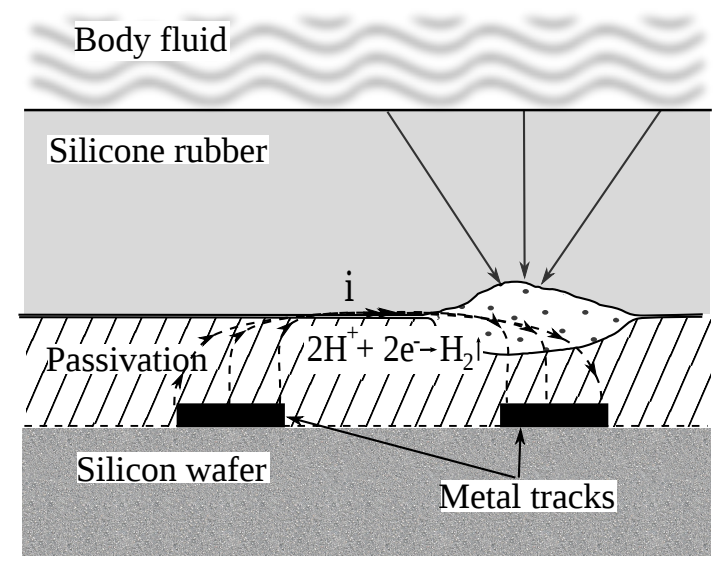

(d) Failure type (ii): electrolysis of condensed water at the virtual cathode.

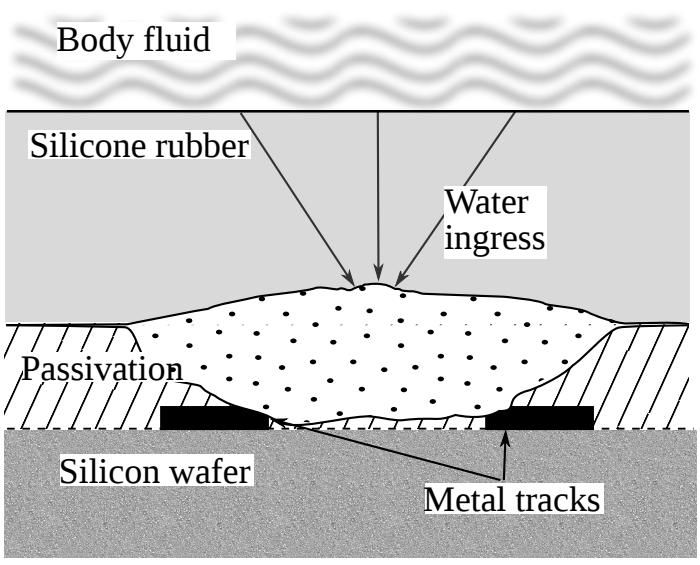

(f) Failure type (ii) and (iii): corrosion of the underlying metal tracks and electrical failure.

Figure 4. Water ingress preceding corrosion of the metal tracks in ICs exposed to high humidity environment. Sketches based on the work by Osenbach, Zell and Knolle. 
Table 1. Accelerated ageing data (failure types (ii) and (iii) combined) recorded from samples maintained at $85{ }^{\circ} \mathrm{C}$ and $85 \% \mathrm{RH}$. The median life, lateral field-strength between tracks and conductivity and stoichiometry of the passivation layer are taken from Osenbach (1993) while the current density is calculated as $J=\sigma \times E$.

\begin{tabular}{cccc|c}
\hline $\begin{array}{c}\text { Median life } \\
h\end{array}$ & $\begin{array}{c}\text { Field-strength - E } \\
\frac{V}{m}\end{array}$ & $\begin{array}{c}\text { Conductivity } \sigma \\
\frac{S}{m}\end{array}$ & Stoichiometry & $\begin{array}{c}\text { Current density - J } \\
\frac{A}{m^{2}}\end{array}$ \\
\hline 250 & $25 \times 10^{6}$ & $1 \times 10^{-6}$ & $\mathrm{~A}$ & 25 \\
350 & $35 \times 10^{6}$ & $3 \times 10^{-7}$ & $\mathrm{~B}$ & 10.5 \\
900 & $25 \times 10^{6}$ & $7 \times 10^{-8}$ & $\mathrm{~B}$ & 1.75 \\
3500 & $10 \times 10^{6}$ & $2 \times 10^{-8}$ & $\mathrm{~B}$ & 0.2 \\
$>10,000$ & $25 \times 10^{6}$ & $1 \times 10^{-10}$ & $\mathrm{C}$ & 0.0025 \\
\hline
\end{tabular}

of the passivation layer.

The main conclusions from our review are that the time to failure may depend on the field-strength applied through the passivation layer, and that a loss of adhesion, or the presence of voids at the encapsulant-passivation interface, even if not close to the bonding pads, does diminish the implant lifetime.

\subsection{Influence of field-strength and current density}

The continuing reduction of the feature sizes in IC technology means that field-strengths are getting larger in applications where the working potentials are determined by off-chip requirements, for example the voltages needed to drive stimulating electrodes. Thus, field-strengths that were considered unusually high have become increasingly common. It is not atypical nowadays to have $20 \mathrm{~V}$ across a $1 \mu \mathrm{m}$ gap between tracks or through a passivation layer, which gives a field of $20 \mathrm{~V} / \mu m \equiv 20 \mathrm{MV} / \mathrm{m}$. Under such fieldstrengths, bias-induced corrosion may considerably reduce the device's expected lifetime. We have analysed a subset of data published in (Osenbach 1993), summarised in the first four columns of table 1, to quantify the effect of the field-strength on expected lifetime. The samples were ICs, produced using a standard CMOS process, see the original paper for more details. A range of passivation layer stoichiometries were used, hence giving a range of conductivities (see table 1). Conduction through the passivation layer is due to the Frenkel-Poole effect, therefore the conductivity of the film does not only depend on its stoichiometry, but also on the applied field-strength (E) as $\sigma_{F-P} \propto e^{\sqrt{E}}$. The samples were all coated with an unnamed RTV silicone rubber and maintained at $85^{\circ} \mathrm{C}$ and $85 \% \mathrm{RH}$ under continuous bias for the duration of the test.

Using the information in Osenbach's paper, we have calculated the current density, through the passivation layer (not through the silicone rubber), see the last column of table 1. For our analysis, only the four first rows of table 1 were used. The entry in the fifth row indicates that there were no failures before the test was terminated, at 


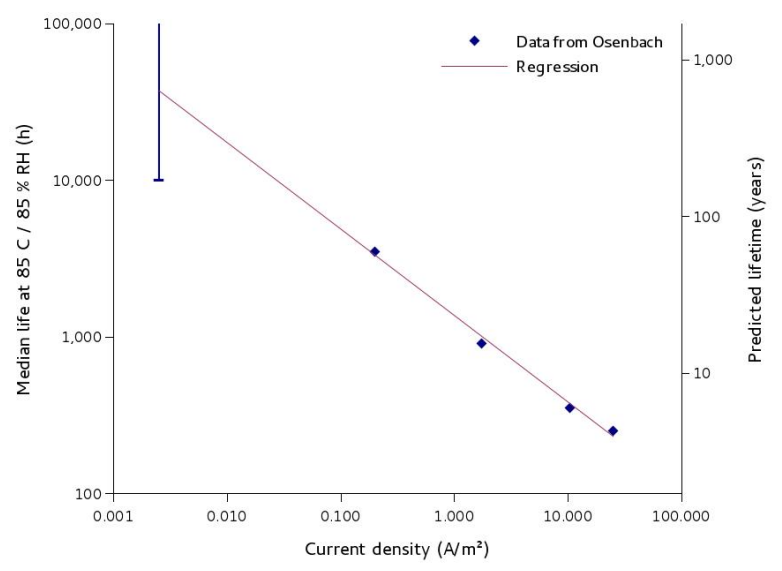

Figure 5. Median life reported by Osenbach as a function of current density and corresponding median life at $37^{\circ} \mathrm{C}$ and $100 \% \mathrm{RH}$ extrapolated using equation 16 .

10,000 hours. The regression line, plotted on figure 5, suggests that 36,840 hours, or 4.2 years, would have been the median time to failure for this last point. Although the experimental data were published more 20 years ago, our regression analysis is novel and shows for the first time that the median life $t_{50 \%}$ is proportional to $1 / \sqrt{J}$. This remarkable result is highly relevant when considering the use of ICs in implantable electronic devices. From section 3.2.2, failures of type (iii) would depend only on the stoichiometry while type (ii) would also depend on the field-strength. This analysis therefore indicates that for the passivation layer stoichiometries used by Osenbach, type (ii) failures dominate (the author did not specify which failure type was actually observed). This may be due to the fact that the current contributes to weakening the adhesion (Osenbach \& Zell 1993) therefore facilitating water condensation which is necessary for the degradation of the passivation layer. Failure type (iii) might be more prominent with more resistive passivation layers.

The three failure types discussed all require the presence of liquid water, which must condense over the surface of the IC. Well applied silicone rubber encapsulation prevents this until adhesion is lost, while with hermetic packages the time until liquid water forms is dependent on the leak rate and package volume. Therefore, while the failure modes were identified with RTV coated ICs, they are likely to be occurring in uncoated ICs since liquid water can form over the active surfaces in both cases.

\section{Expected lifetime of implanted ICs}

In the previous section we have shown that the median life $t_{50 \%}$ of an IC, whether bare or encapsulated in silicone rubber, and operating in a moist environment, is related to the current density through its passivation layer, equation 8. Although most of the semiconductor corrosion research has focused on ICs in plastic packages, often epoxy, it is generally accepted (for references see the papers cited in this section) that $t_{50 \%}$ is 
also a function of the temperature and the relative humidity, equation 9 .

$$
\begin{aligned}
& t_{50 \%} \propto 1 / \sqrt{J} \\
& t_{50 \%} \propto f(T, R H)
\end{aligned}
$$

\subsection{Influence of the temperature}

Functional failure may be defined as an excessive leakage current even before the occurrence of an open or short circuit. This leakage current is related to the surface conductivity which increases with time as the corrosive process progresses (Sim \& Lawson 1979) until an open or short circuit ensues. The failure rate is therefore proportional to the leakage conductivity, and the median life is inversely proportional to the failure rate.

The surface conductivity over bare silicon dice exposed to a moist environment, with constant RH, as a function of the temperature follows an Arrhenius relationship, $\sigma(T)=e^{-\frac{E a}{k T}}$. T is the temperature in Kelvin and $k$ is Boltzmann's constant $\left(8.617 \times 10^{-5}\right.$ $\left.e V K^{-1}\right)$. The situation is however complicated by the fact that the activation energy $E_{a}$ changes with the relative humidity. In Koelmans (1974), for unpassivated silicon dioxide, it decreases from $0.78 \mathrm{eV}$ at $10 \% \mathrm{RH}$ to $0.35 \mathrm{eV}$ at $70 \% \mathrm{RH}$. The nature of the relation between the activation energy and the relative humidity is discussed in section 4.2 .

When silicone rubber is used as encapsulant, it occupies the sites on which the water molecules would adsorb. This limits the formation of continuous layers of water, hence limiting ionic current flow. This only holds true where the silicone rubber does actually adhere to the surface, which depends on the integrated circuit's topography, the cleanliness of its surface prior to encapsulation, the viscosity of the uncured encapsulant and its adhesive properties once cured. Experimentally, silicone rubber encapsulation decreases the leakage conductivity (no longer called surface conductivity since the conduction mechanisms are likely to be different from those observed with unencapsulated samples) (Sbar \& Kozakiewicz 1978, Iannuzzi 1983b). The leakage current is 1 to 2 orders of magnitudes smaller with silicone rubber, therefore $t_{50 \%} \propto$ $e^{\frac{E_{a}}{k T}} \times e^{r}$ where $r_{\text {bare }}=0$ and $2.3<r_{\text {encap }}<4.6$ to reflect this decrease in the magnitude of the leakage current. The failure rates still follow an Arrhenius relationship with the temperature, but the influence of the temperature is steeper. In other words, the activation energy is increased by the presence of the encapsulant. It is also less sensitive to the relative humidity (Sbar \& Kozakiewicz 1978). In Christou \& Wilkins (1977), the activation energy varied from $1.3 \mathrm{eV}$ at $20 \% \mathrm{RH}$ to $1 \mathrm{eV}$ at $80 \%$ using a Dow Corning silicone rubber encapsulant (DC90702). These values are higher than those published in Koelmans (1974), with a narrower variation over the range of $\mathrm{RH}$. 


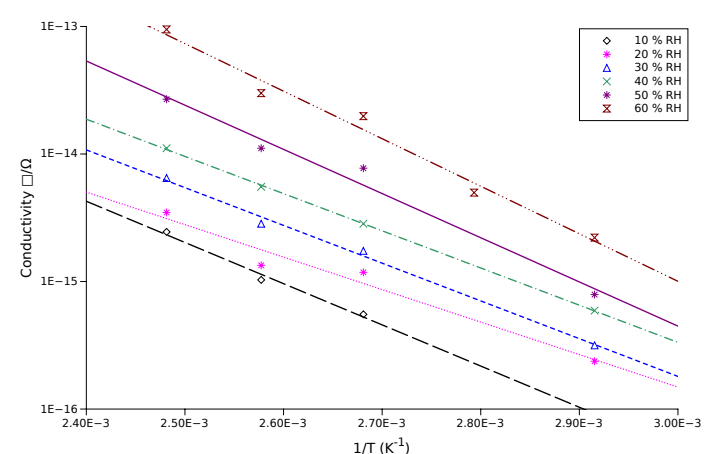

(a) Conductivity as a function of the inverse of the temperature. The relative humidities are given in the legend as a parameters. For each, the activation energy is the slope of the corresponding regression line.

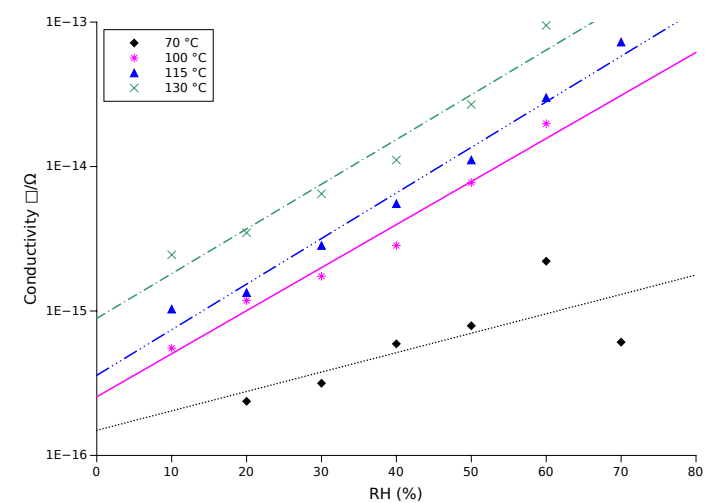

(b) Conductivity as a function of the relative humidity. The temperatures are given in the legend as parameter. The slopes of the regressions lines give the parameter $n$ used in equation 15.

Figure 6. Plot of a subset of data from Weick (1980), for bare aluminium conductors over silicon dioxide on a silicon wafer.

\subsection{Influence of the relative humidity}

The physical nature of the influence of the $\mathrm{RH}$ is the subject of much theoretical discussion (Escobar \& Meeker 2006, Bayle \& Mettas 2010, Klinger 1991, Herr et al. 1980). Koelmans (1974) observed that at high relative humidities, the activation energy tends to that for bulk electrolytic conduction in pure water, which is $0.34 \mathrm{eV}$ over silicon dioxide. Several equations for $f(T, R H)$ have been proposed for plastic packages with epoxy (for reviews see Hallberg \& Peck (1991) and Striny \& Schelling (1981)), but only Sbar \& Kozakiewicz (1978) did it for bare and encapsulated test samples. They tested Ti-Pd-Au metallisation over ceramic, aluminium oxide and silicon nitride, as well as Ti-TiNi-Pt-Au over silicon nitride. They made the assumption that the activation energy varies linearly with the relative humidity and proposed the following equation for the leakage conductivity.

$$
\sigma=e^{a+b \times R H-\frac{c}{k \times T}-\frac{d \times R H}{k \times T}}
$$

Weick (1980) published surface conductivities recorded at several temperatures and relative humidities for three types of test samples: gold conductors and aluminium alloy ( $0.5 \%$ weight copper) over silicon dioxide on a silicon wafer, with or without an extra silicon nitride passivation layer. A subset of this data is plotted in figure 6 . The conductivity increases with increasing temperature at constant relative humidity (Arrhenius relation, fig.6(a)), and with increasing relative humidity at constant temperature (fig. 6(b)). Hence there are two conditions on the 4 parameters of equation 10.

$$
\begin{array}{ll}
c+d \times R H>0 & \forall R H \\
b-\frac{d}{k \times T}>0 & \forall T
\end{array}
$$




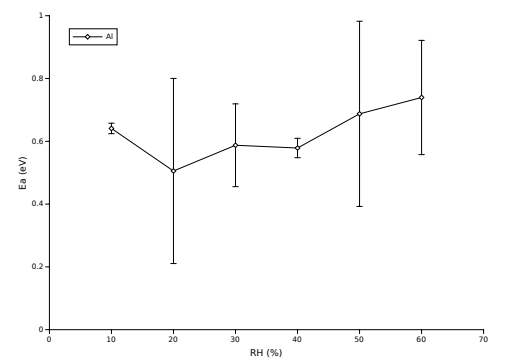

(a) Bare aluminium conductor

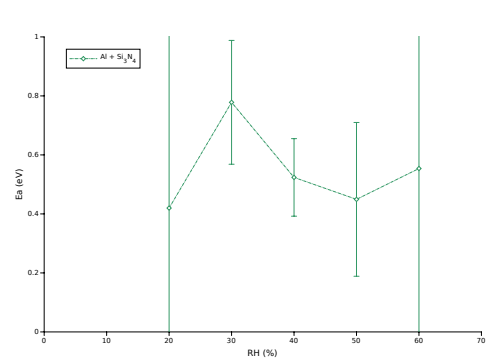

(b) Aluminium coated with $\mathrm{Si}_{3} \mathrm{~N}_{4}$.

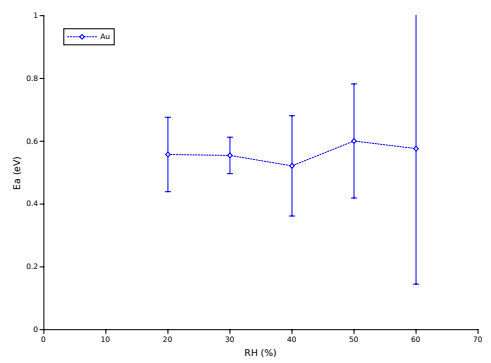

(c) Bare gold conductor.

Figure 7. Activation energy as a function of the relative humidity for the three sample types tested by Weick (1980). The error bars indicate the $95 \%$ confidence interval.

Equation 11 gives the activation energy.

$$
E_{a}=c+d \times R H
$$

Posing

$$
b-\frac{d}{k \times T}=n
$$

at constant temperature, equation 10 can be re-written as equation 15 .

$$
\sigma \propto e^{n \times R H}
$$

This is reminiscent of Koelmans (1974) who also noted that $\sigma_{\text {surface }} \propto e^{\alpha m}$ where $m$ is the number of monolayers adsorbed on the surface, which is to some extent related to the relative humidity (Klinger 1991).

We have calculated the activation energies of Weick's data (see table 2), figure 7 shows how these vary with the relative humidity. The confidence intervals for some points are large, so the data do not corroborate Sbar and Kozakiewicz's assumption that the activation energy varies linearly with the relative humidity (equation 13). Likewise for the constant temperature situation, figure 8 shows how $n$ varies with $1 / T$. Given the size of some of the $95 \%$ confidence interval, it is possible (though inconclusive) that $n$ does increase with T following Sbar and Kozakiewicz's linear assumption (equation 14). We conclude that the model of Sbar \& Kozakiewicz (1978) is not proven. Therefore, new experiments are needed to establish the nature of the relation between the activation energy and the relative humidity, and between $n$ and the temperature.

\subsection{Acceleration factors}

We can now suggest a complete equation for the median life, including the influence of the temperature, relative humidity and current density.

$$
t_{50 \%} \propto e^{E_{a_{R H}} / k T} \times e^{r} \times e^{-n R H} \times \frac{1}{\sqrt{J}}
$$

To use the results of accelerated conductions studies, the ageing effect due to the test conditions is expressed by the acceleration factor $A$ : the ratio between the working 
Table 2. Activation energies with $95 \%$ confidence interval from the data in Weick (1980)

\begin{tabular}{|c|c|c|c|c|c|}
\hline Conductor & $\begin{array}{c}\mathrm{RH} \\
\%\end{array}$ & $\begin{array}{c}\text { Activation energy } \\
\mathrm{eV}\end{array}$ & $\begin{array}{l}\text { Lower bound of CI } \\
\mathrm{eV}\end{array}$ & $\begin{array}{l}\text { Upper bound of CI } \\
\mathrm{eV}\end{array}$ & $\begin{array}{c}\mathrm{p} \text {-value } \\
\%\end{array}$ \\
\hline \multirow{5}{*}{$\begin{array}{l}\mathrm{Au} / \mathrm{Ti} / \mathrm{Pt} \\
\text { tracks over } \\
\mathrm{SiO}_{2}\end{array}$} & 20 & 0.56 & 0.44 & 0.68 & 0.06 \\
\hline & 30 & 0.56 & 0.50 & 0.62 & 0.008 \\
\hline & 40 & 0.52 & 0.36 & 0.68 & 0.19 \\
\hline & 50 & 0.60 & 0.42 & 0.78 & 0.18 \\
\hline & 60 & 0.58 & 0.15 & 1.00 & 2.90 \\
\hline \multirow{6}{*}{$\begin{array}{l}\text { Al tracks } \\
\text { over } \mathrm{SiO}_{2}\end{array}$} & 10 & 0.64 & 0.62 & 0.66 & 0.13 \\
\hline & 20 & 0.51 & 0.21 & 0.80 & 1.79 \\
\hline & 30 & 0.59 & 0.46 & 0.72 & 0.27 \\
\hline & 40 & 0.58 & 0.55 & 0.61 & 0.02 \\
\hline & 50 & 0.69 & 0.39 & 0.98 & 0.98 \\
\hline & 60 & 0.74 & 0.56 & 0.92 & 0.10 \\
\hline \multirow{5}{*}{$\begin{array}{l}\text { Al tracks } \\
\text { over } S i_{3} N_{4}\end{array}$} & 20 & 0.42 & -1.95 & 2.79 & 0.06 \\
\hline & 30 & 0.78 & 0.57 & 0.99 & 0.06 \\
\hline & 40 & 0.52 & 0.39 & 0.66 & 0.06 \\
\hline & 50 & 0.45 & 0.19 & 0.71 & 0.06 \\
\hline & 60 & 0.55 & -1.27 & 2.38 & 0.06 \\
\hline
\end{tabular}

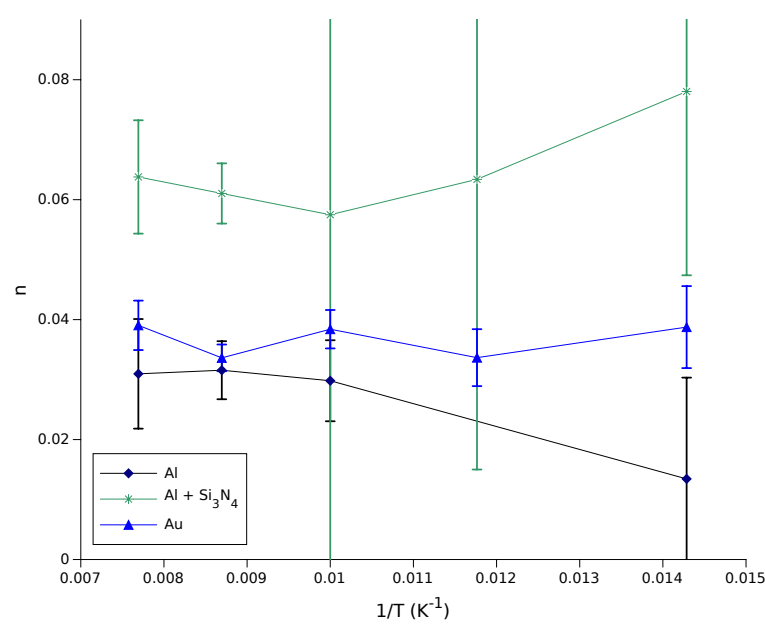

Figure 8. Variation of $\mathrm{n}$ with $1 / \mathrm{T}$ for the three sample types tested by Weick (1980). The error bars indicate the $95 \%$ confidence interval.. 


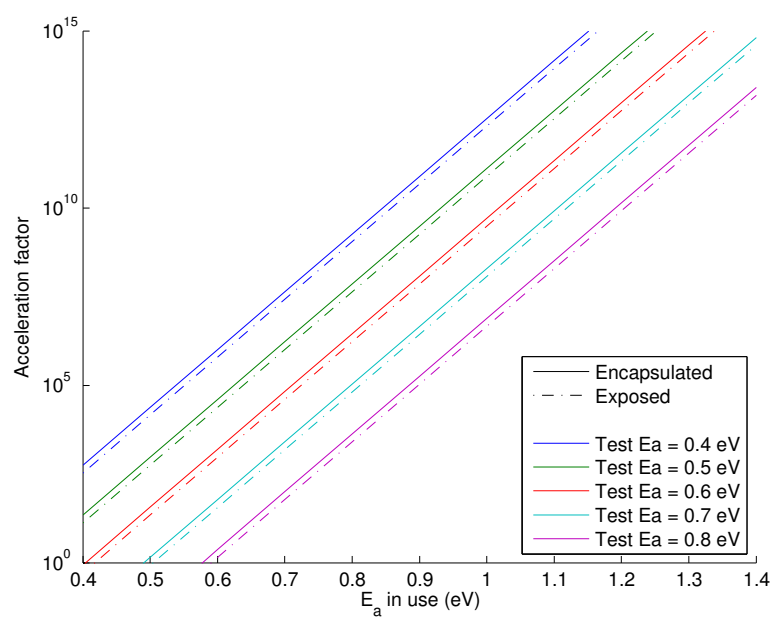

Figure 9. Variation of the acceleration factors with the activation energies during the test (given as a parameter) and in use (along the x-axis). The test is performed at 85 ${ }^{\circ} \mathrm{C}$ and $85 \% \mathrm{RH}$ with bare ICs. The working conditions are in the body, either in a hermetic package, exposed at $10 \% \mathrm{RH}$ (dot-dash lines), or encapsulated, hence at 100 $\%$ RH (solid lines).

lifetime $t_{50 \%, \text { work }}$ and the test lifetime $t_{50 \%, \text { test }}$.

$$
A=\frac{e^{E_{a, \text { use }} / k T_{\text {use }}} \times e^{r_{\text {use }}} \times e^{-n_{\text {use }} R H_{\text {use }}} \times \frac{1}{\sqrt{J_{\text {use }}}}}{e^{E_{\text {a,test }} / k T_{\text {test }}} \times e^{r_{\text {test }}} \times e^{-n_{\text {test }} R H_{\text {test }}} \times \frac{1}{\sqrt{J_{\text {test }}}}}
$$

As illustrated in figure 9, this ratio is very sensitive to small changes of the activation energy. An increase of $0.1 \mathrm{eV}$ in the working activation energy causes a multiplication by 42 while a similar increase of the test activation energy divides the acceleration factor by 26 .

The acceleration factors of figure 9 were calculated using equation 17 with the following parameters, temperatures and relative humidities. The test is performed at $85{ }^{\circ} \mathrm{C}$ and $85 \% \mathrm{RH}$, without encapsulation and with a bias similar to that expected in use, so that $J_{\text {test }} / J_{\text {use }}=1$. The working temperature for medical implants is $37^{\circ} \mathrm{C}$. The working $\mathrm{RH}$ will be $100 \%$ when using silicone rubber encapsulation. Within a hermetic package it is dependent on the packaging conditions and leak rate, and is a function of time as given by equation 3 . We have assumed a constant $10 \%$. The parameters are: $n_{\text {exposed }}=0.051$, $n_{\text {encap }}=0.03$ (Sbar \& Kozakiewicz 1978), $r_{\text {exposed }}=0$ and $r_{\text {encap }}=3$.

One use of this figure is to compare the two protection methods. Consider the hermetic package first. Using the activation energies in table 2 , we can take a value of $0.6 \mathrm{eV}$, both during the test and in use. This corresponds to an activation factor $A_{\text {hermetic }}=937$. As discussed in section 4.1, the activation energy for the same device now encapsulated is higher. Taking $E_{a, \text { use }}=0.8 \mathrm{eV}$ gives an acceleration factor of $A_{\text {encap }}=2.810^{6}$ or $937 \times 42 \times 42 \times 1.7$ where 1.7 is the distance between the solid and dash-dot lines, the compound influence of the relative humidity and encapsulation, through $n$ and $r$. This comparison would indicate that silicone rubber encapsulation may be a better 
protection method for ICs. However, $A_{\text {hermetic }}$ ignores the time taken for the internal relative humidity to reach $R H_{\text {work }}$.

\section{Discussion}

While both protection methods discussed in this paper are used in commercial applications, the hermetic package is by far the more popular. This is probably due to the advantage of lifetime prediction using leak testing. Assuming that the leak rate remains unchanged after years of implantation, which only some sealing method can guarantee, the time it will take for the content of the cavity to reach a critical relative humidity can be estimated using equation 1. Equation 7 offers a straightforward means of quality control as well as the possibility to quickly assess the consequences of any processing alteration.

There is no agreement on what constitutes a critical relative humidity, and the initial internal relative humidity, as well as the later contribution from outgasing, are rarely known. However, while the internal volumes of the packages were large, such issues did not cause much practical concern. With the continued trend towards ever smaller packages, these sources of internal moisture become considerably more significant.

Further, packages will soon reach an internal volume so small that it will no longer be possible to use leak testing as a screening method. While it may still be possible to produce sealed cavities that remain dry for decades inside the body, it will no longer be possible to establish this fact prior to implantation. The lifetime predictability advantage is lost. The introduction of relative humidity sensors inside these new micropackages may provide a means of real time monitoring of the situation (Cirmirakis et al. 2011). Yet, to find commercial applications, any such packages will be required to undergo long-term tests to study their stability in the body. The decision as to the adequacy of a package for a given implantation time will be based on the results of accelerated ageing tests. This statistical approach is the same as that already used for the validation of the silicone encapsulation.

In comparison, silicone rubber encapsulation has long been the subject of such tests, and the results, as analysed in this paper, indicate that this method could provide sufficient protection, provided the current density through the passivation layer is limited. However, although the form of the lifetime equation has been suggested in the literature and extended in these pages (equation 16), the constants of the equation are not known with sufficient accuracy and, as figure 9 suggests, lifetime prediction is very sensitive to these values. Further, integration densities have increased considerably since the devices under test in the papers reviewed here were produced. The influence of the higher field-strengths resulting from this trend can be accounted for using equation 16. However, narrower gaps on the surfaces on which the silicone rubber is applied may affect the efficiency of the cleaning method, and contribute to weaker adhesion. Hence, further tests are also needed to fully characterise this protection method. 


\section{Conclusion}

This paper is concerned with the protection of ICs operating in moist environments, with a special focus on implantable medical electronic devices. We have shown that while it may be possible to produce $\mathrm{mm}^{3}$-volume hermetic packages, lifetime prediction by helium leak test of such devices is no longer possible.

Having analysed previously published data, we have shown for the first time how the lifetime of an IC encapsulated in silicone rubber depends on the current density. This is combined with the effect of the temperature and relative humidity in equation 16 . We have calculated acceleration factors that indicate that silicone rubber encapsulation may be a suitable protection method for bare silicon dice but the corrosion rate of ICs manufactured recently must be studied to obtain reliable activation energies. If encapsulation is used, cleanliness (no ionic contamination) and the long-term stability of the adhesion of the encapsulant to the IC will be crucial. With very small dimensions, the viscosity of the uncured silicone rubber, the stoichiometry of the passivation layer and the field-strengths are also critical.

We are not advocating one method over the other. Even considering the loss of lifetime prediction, the possibility to introduce internal humidity measurements inside micropackages may give greater confidence in this method. Yet, these very small hermetic packages are likely to require more complex fabrication steps and be more expensive. Further, they will probably still rely on silicone rubber encapsulation to protect external metallised areas, such as wire and electrode connection sites.

\section{Acknowledgments}

The authors would like to thank Dr. Schuettler for his continued support and many constructive discussions. This review was undertaken thanks to funding from the UK Engineering and Physical Science Research Council (EPSRC) under grant number EP/F009593/1, and the European Community's Seventh Framework Programme [FP7/2007-2013] under grant number CP-IP 258654.

\section{References}

Balde J W 1991 'The effectiveness of silicone gels for corrosion prevention of silicon circuits: the final report of the IEEE computer society computer packaging committee special task force' IEEE Transactions on Components, Hybrids, and Manufacturing Technology 14(2), 352-365.

Bayle F \& Mettas A 2010 in 'Proceedings of the Reliability and Maintainability Symposium (RAMS), 2010' IEEE pp. 1-6.

Bowman L \& Meindl J D 1986 'The packaging of implantable integrated sensors' IEEE T Bio-Med Eng (2), 248-255.

Brindley G S 1994 'The first 500 patients with sacral anterior root stimulator implants: general description' Paraplegia 32(12), 795-805.

Christou A \& Wilkins W 1977 in 'Proc. 15th Annual Reliability Physics Symposium' pp. 112-119.

Cirmirakis D, Demosthenous A, Saeidi N, Vanhoestenberghe A \& Donaldson N 2011 in 'Proc. IEEE Sensors' pp. 1511-1514. 
DerMarderosian A \& Murphy C 1977 in 'Proc. 15th Annual Reliability Physics Symposium' pp. 92-100.

Donaldson N, Vanhoestenberghe A, Saeidi N, Evans J, Liu X, Cirmirakis D, Demosthenous A \& Schuettler M 2011 in 'Proc. of the Medical Bionics Conference' Melbourne.

Donaldson P E K 1976 'The encapsulation of microelectronic devices for long-term surgical implantation' IEEE T Bio-Med Eng (4), 281-285.

Donaldson P E K 1991 'Aspects of silicone rubber as an encapsulant for neurological prostheses - part 1: Osmosis' Med. Biol. Eng. Comput. 29, 34-39.

Donaldson P E K 1995 'Aspects of silicone rubber as an encapsulant for neurological prostheses - part 3: Adhesion to mixed oxides' Med. Biol. Eng. Comput. 33, 725-727.

Donaldson P E K 1997 'Aspects of silicone rubber as an encapsulant for neurological prostheses - part 4: Two-part rubbers' Med. Biol. Eng. Comput. 35, 283-286.

Donaldson P E K \& Aylett B J 1995 'Aspects of silicone rubber as an encapsulant for neurological prostheses - part 2: Adhesion to binary oxides' Med. Biol. Eng. Comput. 33, 285-292.

Edell D 2003 'Insulating biomaterials research for implantable microelectronic devices' Mat. Res. Soc. Symp. Proc. $\mathbf{7 7 3}$.

Edell D 2004 Vol. 2 of Series on Bioengineering and Biomedical Engineering World Scientific Publishing Co. Pte. Ltd. chapter 3.2 Insulating Biomaterials, pp. 517-579.

Escobar L \& Meeker W 2006 'A review of accelerated test models' Statistical Science 21(4), 552-577.

Fedors R 1980 'Water-treeing as an osmotic phenomenon' Polymer 21(8), 863 - 865.

Gerding H 2007 'A new approach towards a minimal invasive retina implant' Journal of Neural Engineering 4(1), S30.

Hallberg Ö \& Peck D S 1991 'Recent humidity accelerations, a base for testing standards' Quality and Reliability Engineering International 7(3), 169-180.

Herr E A, Poe A \& Fox A 1980 'Reliability evaluation and prediction for discrete semiconductors' IEEE Transactions of Reliability R-29(3), 208-216.

Howl D A \& Mann C A 1965 'The back-pressurising technique of leak-testing' Vacuum 15 (7), 347-352.

Iannuzzi M 1981 'Development and evaluation of a preencapsulation cleaning process to improve reliability of HIC's with aluminum metallized chips' IEEE Transactions on Components, Hybrids, and Manufacturing Technology 4(4), 429-438.

Iannuzzi M 1983a 'Bias humidity performance and failure mechanisms of nonhermetic aluminum SIC's in an enviornment contaminated with Cl2' IEEE Transactions on Components, Hybrids, and Manufacturing Technology 6(2), 191-201.

Iannuzzi M $1983 b$ 'Reliability and failure mechanisms of nonhermetic aluminum SIC's: Literature review and bias humidity performance' IEEE Transactions on Components, Hybrids, and Manufacturing Technology 6(2), 181-190.

Jarvis J C \& Salmons S 2001 'The application and technology of implantable neuromuscular stimulators: an introduction and overview' Medical Engineering and Physics 23(1), 3-7.

Jezernik S, Craggs M D, Grill W M, Creasey G \& Rijkhoff N J M 2002 'Electrical stimulation for the treatment of bladder dysfunction: current status and future possiblities' Neurological Research 24(5), 413-430.

Klinger D 1991 'Humidity acceleration factor for plastic packaged electronic devices' Quality and reliability engineering international $\mathbf{7}(5), 365-370$.

Koelmans H 1974 in 'Reliability Physics Symposium, 1974. 12th Annual' pp. 168 -171.

Lantz, L. I \& Pecht M 2003 'Ion transport in encapsulants used in microcircuit packaging' Components and Packaging Technologies, IEEE Transactions on 26(1), $199-205$.

Lertmanorat Z, Montague F W \& Durand D M 2009 'A flat interface nerve electrode with integrated multiplexer' IEEE Transactions on Neural Systems and Rehabilitation Engineering 17(2), 176182.

Ng D C, Bai S, Yang J, Tran N \& Skafidas E 2009 'Wireless technologies for closed-loop retinal prostheses' Journal of Neural Engineering 6(6), 065004.

Olberg R \& Bozarth J 1976 'Factors contributing to the corrosion of the aluminum metal on 
semiconductor devices packaged in plastics' Microelectronics Reliability 15(6), 601 - 611.

Osenbach J S \& Zell J L 1993 'Corrosion of thin film aluminum metallization: conformal coating materials' IEEE Transactions on Components, Hybrids, and Manufacturing Technology 16(3), 350-359.

Osenbach J W 1993 'Water-induced corrosion of materials used for semiconductor passivation' $J$. Electrochem. Soc. 140(12), 3667-3675.

Osenbach J W 1996 'Corrosion-induced degradation of microelectronic devices' Semiconductor Science and Technology 11(2), 155-162.

Osenbach J W \& Knolle W 1992 'Behavior of a-SiN:H and a-SiON:H films in condensed water' J. Electrochem. Soc 139, 3346-51.

Qi H, Vichare N, Azarian M \& Pecht M 2008 'Analysis of solder joint failure criteria and measurement techniques in the qualification of electronic products' Components and Packaging Technologies, IEEE Transactions on $\mathbf{3 1}(2), 469-477$.

Rijkhoff N J M 2004 'Neuroprostheses to treat neurogenic bladder dysfunction: current status and future perspectives' Child's Nervous System 20, 75-86.

Rizzo J, Wyatt J, Humayun M, de Juan E, Liu W, Chow A, Eckmiller R, Zrenner E, Yagi T \& Abrams G 2001 'Retinal prosthesis: an encouraging first decade with major challenges ahead.' Ophthalmology 108, 13-4.

Rothermel A, Liu L, Aryan N P, Fischer M, Wuenschmann J, Kibbel S \& Harscher A 2009 'A CMOS chip with active pixel array and specific test features for subretinal implantation' IEEE Journal of Solid-State Circuits 44(1), 290-300.

Sbar N L \& Kozakiewicz R P 1978 in 'Proc. 16th Annual Reliability Physics Symposium' pp. 161-178.

Scamans G \& Rehal A 1979 'Electron metallography of the aluminium-water vapour reaction and its relevance to stress-corrosion susceptibility' Journal of Materials Science 14, 2459-2470.

Schuettler M, Schatz A, Ordonez J S \& Stieglitz T 2011 in 'Proc. 33rd Annual International Conference of the IEEE EMBS' pp. 2296-2299.

Sim S \& Lawson R 1979 in '17th Annual Reliability Physics Symposium' IEEE pp. 103-112.

Sinnadurai N 1996 'Plastic packages survive where hermetic packages fail' Microelectronic Reliability 36, 1001-18.

Striny K \& Schelling A 1981 'Reliability evaluation of aluminum-metallized MOS dynamic RAM's in plastic packages in high humidity and temperature environments' IEEE Transactions on Components, Hybrids, and Manufacturing Technology 4(4), 476 - 481.

Thomas R 1976 'Moisture, myths, and microcircuits' IEEE Transactions on Parts, Hybrids, and Packaging 12(3), 167-171.

Traeger R 1977 'Nonhermeticity of polymeric lid sealants' IEEE Transactions on Parts, Hybrids, and Packaging 13(2), 147-152.

Vanhoestenberghe A \& Donaldson N 2011 'The limits of hermeticity test methods for micropackages' Artificial Organs 35(3), 242-244.

Weick W W 1980 'Acceleration factors for IC leakage current in a steam environment' IEEE Transactions of Reliability R-29(2), 109-115.

Wong C, Segelken J \& Balde J 1989 'Understanding the use of silicone gels for nonhermetic plastic packaging' IEEE Transactions on Components, Hybrids, and Manufacturing Technology 12(4), $421-425$.

Zhao P \& Pecht M 2003 'Field failure due to creep corrosion on components with palladium pre-plated leadframes' Microelectronics Reliability 43(5), 775 - 783.

Zrenner E, Wilke R, Bartz-Schmidt K U, Gekeler F, Besch D, Benav H, Bruckmann A, Porubska K, Kusnyerik A, Sachs H, Peters T, Wilhelm B, Greppmaier U, Harscher A, Kibbel S, Wrobel W \& Stett A 2009 in 'Proc. 2nd International Conference on Biomedical Engineering and Informatics (BMEI)' pp. 1-4. 